\title{
Aprendizagem organizacional: a experiência vivida por bibliotecários de uma biblioteca universitária
}

\author{
Marouva Fallgatter Faqueti \\ Sigrid Karin Weiss Dutra \\ João Bosco da Mota Alves \\ Cristiano José Castro de Almeida Cunha \\ Universidade Federal de Santa Catarina - UFSC, Brasil
}

ORIGINAL

\begin{abstract}
Resumo
Compreender como acontece o processo de Aprendizagem Organizacional (AO) a partir da perspectiva dos bibliotecários no cotidiano laboral é relevante, pois, a partir dessa compreensão, é possível obter subsídios para melhorar as práticas de gestão em bibliotecas. Neste contexto, o objetivo do artigo é descrever a percepção dos bibliotecários de uma Biblioteca Universitária sobre suas experiências em processos de AO. O estudo adotou a abordagem qualitativa de pesquisa e utilizou como instrumento de coleta de dados a entrevista não estruturada. Foram entrevistados seis bibliotecários ocupantes de cargos de gestão intermediária de uma biblioteca universitária. A análise temática das narrativas foi estruturada a partir do framework desenvolvido por Crossan, Lane e White, que explicam o processo de AO por meio dos 4ls (intuição, interpretação, integração e institucionalização). Agregou-se também uma análise sobre a aprendizagem em rede mediada por relacionamentos intra e interorganizacionais. Os resultados indicam que o modelo dos 4ls pode ser aplicado como uma estrutura conceitual para a identificação e compreensão dos processos $\mathrm{AO}$ em bibliotecas. Sugere-se o desenvolvimento de pesquisas adicionais envolvendo servidores ocupantes de outras funções, bem como estudos que envolvam relacionamentos à distância. Considerando que este estudo especificamente está focado no movimento dos 4 Is, sentido feed-forward (do nível individual ao organizacional), sugere-se também que novos estudos devem ser conduzidos para compreender o processo de aprendizagem fluindo em sentido inverso - Feedback (sentido da organização para o indivíduo). A baixa relacionalidade e a pequena representatividade da biblioteca junto a órgãos ou setores da instituição de origem foram causas apontadas como inibidoras da aprendizagem organizacional no nível intraorganizacional.
\end{abstract}

Palavras-chave

Aprendizagem em grupo; aprendizagem individual; aprendizagem organizacional; biblioteca universitária; biblioteca acadêmica; bibliotecário

\section{Organizational learning: lived experience for librarians of a university library}

\begin{abstract}
Understanding how the Organizational Learning (OL) process occurs, from the contribution of librarians in their daily work is relevant because from such understanding is possible to obtain subsidies to deepen discussions on practices in libraries management. Thus, this study aimed to know the perception of librarians about their experiences in participating in $\mathrm{OL}$ processes in their workplace having as scenario the academic Library of Santa Catarina. It is characterized as an exploratory qualitative study. It was used as the data collection instrument an unstructured interview applied along to librarian's occupants of middle management positions in a university library. Thematic analysis of the narratives was structured using the framework developed by Crossan, Lane and White that explains the process of OL in the 4I's (intuition, interpretation, integration and institutionalization) focusing on feed-forward sense. The results indicate that the model may be applied as a conceptual framework for the identification and understanding of OL processes in libraries. It is suggested that further research must be developed involving employers of other functions aimed to increase the understanding of the $\mathrm{OL}$ processes in academic libraries, as well as studies covering distance relationships. Whereas this study specifically is focused on the movement of the $4 \mathrm{l} s$, meaning feed-forward it is suggested also that new studies must be conducted to understand the learning process flowing in inverse sense -Feedback (sense of the organization to the individual).
\end{abstract}

Keywords

Academic library; individual learning; learning group; librarian; organizational learning 


\section{Introdução}

O acesso ao universo informacional nas últimas duas décadas sofreu uma grande mudança. O surgimento da web alterou a forma das pessoas se conectarem, socializarem seus conhecimentos e produzirem novos repertórios (SANTOS, CATARINO, 2016). Nesse novo cenário, as bibliotecas necessitam, continuamente, repensar os seus serviços e produtos, para incorporar os avanços tecnológicos e atender às novas demandas (CUNHA, 2010).

O bibliotecário, esteja ele atuando junto aos setores públicos, privados ou do terceiro setor, necessita estar constantemente aprendendo. O conhecimento adquirido durante a sua formação acadêmica é reconstruído ao longo da atuação profissional, tanto pelos caminhos formais da educação continuada quanto por caminhos informais, que utilizam as redes sociais, comunidades de prática, trabalhos em equipe, dentre outros.

Cabe aos gestores de bibliotecas o desafio de criar condições para que a aprendizagem individual encontre solo fértil para ser transformada em aprendizagem organizacional. Segundo Crossan, Lane e White (1999), o processo de AO inicia com a aprendizagem do indivíduo, segue para o nível grupal e se transforma em organizacional. Portanto, o elemento humano é a chave que abre as portas para o seu desencadeamento.

No campo da Biblioteconomia e Ciência da Informação, o tema de AO é emergente e pesquisas empíricas são incipientes (CASTRO; COSTA, 2014, FAQUETI; ALVES; STEIL, 2016). Visando reduzir essa lacuna, o objetivo deste artigo é identificar a percepção dos bibliotecários de uma Biblioteca Universitária sobre suas experiências em processos de aprendizagem organizacional.

$\mathrm{Na}$ sequência, são apresentados os fundamentos teóricos e conceituais sobre Aprendizagem Organizacional e Bibliotecas, os procedimentos metodológicos adotados na pesquisa, os resultados alcançados e as considerações finais.

\section{Aprendizagem organizacional e o seu processo}

Estudos na área de Aprendizagem Organizacional (AO) são desenvolvidos em múltiplas áreas do conhecimento, com olhares da psicologia, desenvolvimento organizacional, ciência administrativa, sociologia, teoria organizacional, estratégia, gerenciamento da produção, antropologia cultural, dentre outras (ANTAL et al., 2001; EASTERBY-SMITH, 1997; STEIL et al., 1999; BONTIS; CROSSAN; HULLAND, 2002).

O conceito de Aprendizagem Organizacional (AO), ao longo dos seus 50 anos de estudo, permanece em contínua reconstrução. Para efeito deste trabalho, entende-se AO como "[...] um processo, uma construção social que transforma o conhecimento criado pelo indivíduo em ações institucionalizadas em direção aos objetivos organizacionais" (ANGELONI; STEIL, 2011, p.121). Ela envolve processos pelos quais o conhecimento criado pelos indivíduos de uma forma organizada é transformado e incorporado ao sistema de conhecimento da organização.

Segundo Snyder e Cummings (1998), a aprendizagem é organizacional quando:

\footnotetext{
a) é realizada para alcançar propósitos organizacionais;

b) é compartilhada ou distribuída entre os membros da organização; e

c) os resultados da aprendizagem são incorporados a sistemas, estruturas, procedimentos e cultura organizacional.
}

Dentre as teorias existentes sobre Aprendizagem Organizacional (AO) destaca-se as abordagens de March (1991), Argyris e Schon (1978), Crossan, Lane, White, (1999). Segundo March (1991), o processo de renovação estratégica organizacional ocorre por uma tensão entre duas vias: explotação (utilização do que já foi aprendido) e exploração (assimilação de novas aprendizagens). Argyris e Schon (1978) propõem um modelo de aprendizagem que envolve mudança cognitivas e comportamentais podendo ocorrer em um ciclo simples (ajustes/correções baseados em um único feedback sem alterar normas e estratégias organizacionais) ou em ciclo duplo (quando a correção de um erro requer um duplo feedback e subsequente reestruturação de suas normas ou estratégias organizacionais).

Crossan, Lane e White (1999) desenvolveram um framework mais complexo, no qual o processo de AO possui uma natureza dinâmica e ocorre nos níveis individual, grupal e organizacional, por meio de quatro processos (4ls) - Intuição, Interpretação, Integração e Institucionalização. Além de ocorrer em diferentes níveis, o processo de AO apresenta dois sentidos: a) do indivíduo para a organização (feed-forward); e b) da organização para o indivíduo (feedback), como pode ser observado na figura 1. 


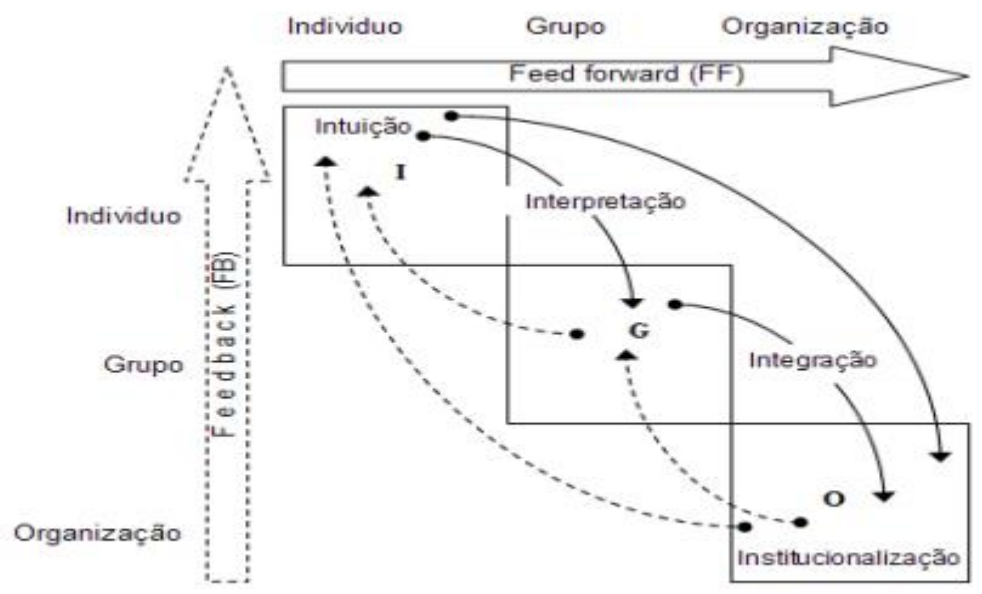

Figura 1 - Processo de Aprendizagem Organizacional

Fonte: Crossan, Lane e White (1999, tradução nossa)

O framework está fundamentado em quatro premissas (CROSSAN; LANE; WHITE, 1999):

a) premissa 1: a aprendizagem organizacional envolve uma tensão entre assimilar novas aprendizagens (exploração) e usar o que foi aprendido (explotação);

b) premissa 2: a aprendizagem organizacional é multinível: indivíduo, grupo e organização;

c) premissa 3: os três níveis da aprendizagem organizacional estão ligados por processos sociais e processos psicológicos: intuição, interpretação, integração e institucionalização (4ls);

d) premissa 4: a cognição afeta a ação (e vice-versa).

Conforme Crossan, Lane e White (1999), o indivíduo é o responsável pelo processo de intuição: um processo subjetivo com base em insights. Frequentemente ocorre de forma espontânea e tácita (difícil de ser verbalizada).

O segundo processo é o da interpretação: o indivíduo, por meio, principalmente, da linguagem, expressa suas ideias, explica seus sentimentos, palpites ou sensações. Uma vez que as "coisas" são nomeadas, os indivíduos podem fazer conexões mais explícitas e estabelecer interações. Interpretar é uma atividade social que cria e refina a linguagem comum, esclarece imagens e facilita a compreensão.

O processo de integração refere-se ao momento em que o conhecimento intuído e interpretado evolui para uma compreensão compartilhada entre membros do grupo, podendo avançar para novos significados.

Por fim, o processo de institucionalização ocorre quando os resultados do processo de integração são incorporados em sistemas, estruturas, estratégias, rotinas e práticas organizacionais. É importante ressaltar que a abordagem da AO apresentada por Crossan, Lane e White (1999) é diferente da visão simples da soma da aprendizagem de seus membros, como afirmaram Fiol e Lyles (1985).

Os processos de $\mathrm{AO}$ podem ocorrer tanto no nível macro (sistema organizacional) quanto nos seus subsistemas (departamentos, setores, unidades). Considerando que esses subsistemas produzem conhecimento, Argote e Ophir (2002) indicam que a articulação de redes internas entre as diversas unidades que compõem uma organização é importante para que ocorra a aprendizagem e melhore o seu desempenho. As autoras consideram que, dentro de uma mesma organização, a boa qualidade dos relacionamentos intraorganizacionais contribui para a transferência de conhecimentos entre unidades. Ou seja, uma unidade é afetada, de maneira positiva, pela experiência de outra- (ARGOTE, 2011).

Assim como redes de aprendizagem intraorganizacionais acontecem nas organizações, Knight (2002) chama a atenção para a existência de redes de aprendizagem no nível interorganizacional. Crossan, Maurer e White (2011), ao refletirem sobre os avanços dos estudos sobre AO na última década, pontuam a necessidade da ampliação das pesquisas para além do contexto organizacional. Outros pesquisadores sobre AO apontam a mesma necessidade-(ANTONELLO, GODOY, 2009, 2010, 2011). Neste sentido, Mozzato e Grzybovski (2011) propuseram a inclusão do nível de Aprendizagem Interorganizacional (AIO) como uma ampliação do modelo apresentado por Crossan Lane e White (1999) (figura 1). 
Estudos sobre AIO emergiram a partir dos anos 1990 e a análise da literatura permite afirmar que suas bases teóricas ainda estão em construção. A revisão teórica de Mariotti (2012) identificou que o constructo "Aprendizagem Interorganizacional" não possui uma definição consensual. Diferentes nomenclaturas têm sido utilizadas, como: "aprendizagem interorganizacional", "redes de aprendizagem" e "aprendizagem em nível de redes". A falta de uma definição clara do conceito e a ausência de uma terminologia comum têm contribuído para gerar confusões.

Segundo Mariotti (2012), o conceito de Aprendizagem Interorganizacional é utilizado em três distintas perspectivas:

\author{
a) criação coletiva de conhecimento; \\ b) criação de regra de interação em redes; e \\ c) aquisição e transferência de conhecimentos.
}

Para o autor, todas as perspectivas têm bases funcionalistas e focam nos potenciais benefícios da colaboração entre organizações e nas relações entre atores, mais do que no processo de colaboração entre organizações. Os estudos revistos por Mariotti (2012) contribuem pouco para esclarecer como o conhecimento se torna interorganizacional.

\title{
3 Bibliotecas universitárias
}

Desde que surgiram as primeiras universidades, suas bibliotecas têm evoluído na busca de superar os desafios emergentes e atender às novas demandas, mas sempre permaneceram com o foco na sua essência: oferecer acesso ao conhecimento. (CUNHA, 2010). Para Fujita (2006), a Biblioteca Universitária é "[...] Um sistema de informação que é parte de um sistema mais amplo, que poderia ser chamado sistema de informação acadêmico, no qual a geração de conhecimentos é o objeto da vida universitária". Lubisco (2014) amplia essa concepção ao considerar que a função da Biblioteca Universitária é respaldar o desenvolvimento institucional relacionado aos programas de ensino, pesquisa, extensão e inovação.

O elemento "Cultura" igualmente não pode ser desconsiderado. A atuação consciente de bibliotecários em bibliotecas acadêmicas valorizam e transformam o espaço sociocultural da comunidade onde elas estão inseridas, pois promovem o consumo e a produção cultural-(SANCHES, 2010). Diversos artigos enfocam sua importância e narram experiências de ações culturais, desenvolvidas no âmbito das bibliotecas (FLUZZER, 1983; SILVA, SOUZA E MORAES,1999; RIBEIRO; CAVALVANTI, 2011; RODRIGUES, 2015).

Para que a biblioteca seja um componente importante de uma instituição de ensino superior, ela deve ser posta a serviço das estratégias institucionais, ter capacidade para construir e projetar saber, e estar vinculada à realidade produtiva e à comunidade (FIGUEIREDO, 2014). Para Lück e outros (2000), as universidades e bibliotecas são agências sociais organizadas com a missão de servir a sociedade enquanto instâncias criadoras e propulsoras do conhecimento, e estimuladoras e facilitadoras do acesso a esse conhecimento.

O contexto atual é caracterizado pela mudança, interatividade e instantaneidade, em que as tecnologias da informação e comunicação influem sobre como as bibliotecas produzem, armazenam, difundem, usam e preservam a informação. Nesse contexto dinâmico e complexo, é fundamental que os profissionais que nelas atuam se incorporem a um processo contínuo de aprendizagem. As questões que permeiam o espaço das Bibliotecas Universitárias têm apresentado novos desafios, que envolvem: um novo conceito de biblioteca; novas posturas de gestão; nova estrutura organizacional; e a criação de novos espaços que ofereçam os meios necessários à construção do conhecimento.

O aumento do número dos documentos eletrônicos, a digitalização e virtualização de conteúdos e serviços têm exigido dos bibliotecários novas habilidades e competências para atender às necessidades emergentes e garantir o valor da biblioteca junto aos seus usuários. O bibliotecário, nesse novo cenário, deixa de ser um mero mediador entre a informação e o usuário e passa a ser um valioso recurso educativo, capaz de participar ativamente do processo de ensino, em uma participação ativa, que implica em prestar serviços e instruções independentemente do lugar, tempo ou suporte.

A ampliação da oferta de ensino superior e a mudança de paradigma na educação, passando do foco no ensino para o foco na aprendizagem, estão levando as bibliotecas a adotar um novo modelo, transformando-se em plataformas de aprendizagem, na qual se integrarão novas tecnologias de informação e comunicação, com a convergência de diversos recursos e possibilidades, virtuais ou presenciais, ampliando a interação social e interpessoal (AMANTE; PLACER; COSTA 2009). Um modelo que, segundo Carneiro e Saro (2009), deve combinar os serviços tradicionais das bibliotecas, centrados nos documentos, com novos serviços, centrados no estudante, mediante a oferta de serviços destinados a facilitar o processo de aprendizagem e acesso à informação, focando também na promoção da formação de docentes e alunos, para que estes utilizem e tirem 
maior proveito dos novos recursos e ferramentas disponibilizados. Assim, as bibliotecas se convertem em promotoras da aprendizagem, ou seja, em centros ativos de recursos para a aprendizagem, docência e pesquisa.

Em síntese, a Biblioteca Universitária caminha, cada vez mais, para ser reconhecida e assumida na instituição como centro de conhecimento e de aprendizagem. Esse novo modelo está centrado em:

a) processos de comunicação e relacionamentos;

b) compartilhamento de recursos informacionais e tecnológicos; e

c) fortalecimento de políticas que fomentem a gestão do conhecimento e aprendizagem organizacional e interorganizacional.

\section{Procedimentos metodológicos}

Esta pesquisa se caracteriza como exploratória e qualitativa. Este tipo de abordagem possibilita maior compreensão dos processos e de seus significados no contexto do problema (MALHOTRA, 2001).

O grupo de informantes envolvidos no estudo foi composto por seis bibliotecários de uma Biblioteca Universitária do Estado de Santa Catarina. A seleção dos entrevistados se deu por conveniência, em função da sua proximidade e facilidade de contato. Privilegiou-se, também, neste processo de escolha intencional, indivíduos ocupantes de funções gerenciais com diferentes períodos de experiência profissional na instituição, por se considerar que este fator poderia interferir nas percepções dos informantes.

Como método de coleta de dados, optou-se pela entrevista não estruturada, pois, segundo Minayo (2010), ela permite liberdade para o entrevistado abordar o tema proposto. Esse modelo de entrevista é utilizado quando se pretende obter o maior número possível de informações sobre determinado tema, segundo a visão dos entrevistados.

As entrevistas procuraram desvelar experiências nas quais os sujeitos perceberam que seus aprendizados ou conhecimentos contribuíram para modificar algum serviço ou implantar uma inovação na biblioteca ou na instituição à qual eles estão vinculados, ou seja, uma experiência na qual tenha ocorrido um processo de $A O$. Antes da entrevista, os informantes foram orientados quanto ao objetivo acadêmico da atividade, quanto à sua liberdade para desistir da conversação em qualquer momento e também sobre o tratamento confidencial dos dados por eles fornecidos. Por fim, cada um assinou o Termo de Consentimento Livre e Esclarecido.

As entrevistas foram gravadas e transcritas. Na sequência, as transcrições foram transferidas para o software Atlas.ti e analisadas de acordo com os princípios da análise temática proposta por Braun e Clarke $(2012,2014)$. O Atlas.ti mostrou-se uma importante ferramenta para a codificação das narrativas associadas às categorias temáticas de análise pré-estabelecidas: intuição, interpretação, integração, institucionalização e aprendizagem em rede.

\subsection{Caracterização do ambiente do estudo}

O objeto de estudo é um Sistema de Bibliotecas criado em 1977, cuja missão é "Participar no processo de disseminação da informação e do conhecimento de forma articulada, para o desenvolvimento das atividades de ensino, pesquisa, extensão e à administração da Universidade". Sua equipe é composta por 103 funcionários, dos quais 44 são bibliotecários. É uma unidade organizacional vinculada à Reitoria. Sua estrutura organizacional é constituída de uma direção, responsável pela coordenação geral do sistema de bibliotecas, formado por dez bibliotecas (multicampi) e coordenado pela Biblioteca Central. Esta unidade coordenadora tanto presta serviços à comunidade do campus sede, como desenvolve ações para padronizar e oferecer os mesmos serviços a todas as unidades do sistema. Para atender às suas demandas, ela atua de forma colaborativa, por exemplo, criando grupos de trabalho ou comissões para assessorar em temas específicos como: "Desenvolvimento de Coleções", "Gestão do Conhecimento" e "Mapeamento de Processos".

\subsection{Caracterização dos respondentes}

Foram entrevistados seis bibliotecários que trabalham na biblioteca central e exercem funções gerenciais de nível intermediário (quadro 1). 


\begin{tabular}{|c|c|l|}
\hline Bibliotecário(a) & Tempo de atuação na instituição & \multicolumn{1}{|c|}{ Chefia-Setor de trabalho } \\
\hline P1 & 4 anos & Referência/noturno \\
\hline P2 & 6 anos & Coleções Especiais \\
\hline P3 & 4 anos & Divisão de Assistência ao Usuário \\
\hline P4 & 7 anos & Circulação \\
\hline P5 & 8 anos & Circulação e recuperação da informação \\
\hline P6 & 2 anos & Tratamento Técnico \\
\hline
\end{tabular}

Quadro 1 - Caracterização dos respondentes

Fonte: Elaborado pelos autores (2016)

Pode-se observar no quadro 1 que o tempo de trabalho na instituição varia entre dois e oito anos, sendo três com até quatro anos e três entre seis e oito anos. Quanto aos setores onde atuam, percebe-se uma predominância de respondentes que desenvolvem suas atividades nas áreas fins, ou seja, em contato direto com os usuários (Referência, Divisão de Assistência ao Usuário, Circulação, e Coleções Especiais) e somente um respondente atua nos serviços meios (Tratamento técnico). Os resultados da pesquisa e discussões são apresentados a seguir.

\section{Resultados e discussões}

Os conteúdos das entrevistas com os bibliotecários ocupantes de cargos de gestão intermediária foram analisados individualmente. Durante o processo de análise, buscou-se identificar, nas narrativas, as experiências vividas pelos entrevistados, desde a motivação geradora de uma ideia até a sua implementação na biblioteca, e sua relação com o framework dos 4ls (fluxo feed-forward) descrito no referencial teórico. Processos relacionados com possíveis aprendizados em rede intra ou interorganizacionais também foram observados.

Seguindo o framework de Crossan, Lane e White (1999) e as ideias de Argote e Ophir (2002), a organização da apresentação dos resultados estrutura-se em cinco partes: intuição, interpretação, integração, institucionalização e aprendizagem em redes. No início de cada subseção apresenta-se uma breve descrição teórica para facilitar a sua compreensão.

\subsection{Intuição}

A primeira etapa do modelo de Crossan, Lane e White (1999) ocorre no nível individual. É um processo caracterizado como subjetivo e tem base em insights que surgem quando um indivíduo enfrenta um problema.

Para se entender como as ideias surgem no ambiente de trabalho do bibliotecário, é importante perceber quais são as fontes motivadoras que desencadeiam esse processo. A análise das entrevistas permitiu reconhecer dois motivos significativos:

a) Identificação de um problema que precisa ser solucionado. Exemplos de problemas citados como fontes geradoras de ideias são: necessidade de atrair mais usuários para utilizarem a biblioteca; barulho na biblioteca; livros devolvidos com pequenas folhas de papel de marcação colados nas páginas;

b) identificação de oportunidade para organizar um novo serviço, sem vinculação direta com a resolução de problemas. Exemplos de ideias que surgiram: organização de uma exposição de corujas; organização de uma atividade de pintura na biblioteca.

Segundo os informantes, as ideias (tanto para solucionar um problema quanto relacionadas com a identificação de oportunidades de melhoria) emergem de quatro formas:

a) contato com uma fonte externa que inspira:

- "[...] Às vezes a gente vê uma experiência bem-sucedida em algum lugar, seja através da literatura, você lê um artigo e você se dá conta: 'ahhh!!! Isso aqui se aplica no meu trabalho" (P1): 
- "[...] Elas estavam na livraria, viram que ele tem uma estante com exposição de corujas e surgiu a ideia [...]" (P3):

- "Eu senti a necessidade de buscar literatura, de ver como estava acontecendo, e também verificar como era essa experiência em outras universidades" (P4);

- "[...] Também estudamos muito [...] Temos grupos de pesquisa (P5);

b) acolhimento de sugestões externas: "[...] Os próprios usuários trazem sugestões e dúvidas". (P5)

c) resgate de uma experiência vivida: "[...] Na verdade, surgiu de uma ideia do Léo. Ele viu o projeto acontecer [em outra biblioteca] e fez a primeira seção piloto na nossa biblioteca [...]". (P1)

d) reflexão individual que gera uma ideia:

Aí comecei a olhar para aqueles post-it [tiras de papeis adesivas coladas nos livros devolvidos]. Comecei a tirar e pensei: a gente tem que fazer alguma coisa com eles. Ai pensei: vamos fazer uma campanha e deixar num lugar, para que eles mesmos possam tirar. Aí colocamos uns acrílicos, colocamos uns post-its dentro e fizemos a campanha pedindo para eles tirarem dos livros e depositarem ali... (P5)

Outra questão foi o livro Jardim Secreto (aqueles de colorir), eu estava vindo trabalhar e tinha acabado de ganhar este livro, aí pensei: olha, se a gente conseguisse usar esse livro de alguma forma na biblioteca... (P5)

e) afinidade pessoal com o tema: "Por ela fazer coleção, ela tem esse olhar mais afinado, ela faz coleção de corujas”. (P1)

Em síntese, os relatos obtidos permitem afirmar que o processo de intuição é ativado por dois mecanismos: a) a percepção de um problema; ou b) a identificação de uma oportunidade no ambiente de trabalho. Além disso, as fontes geradoras de ideias estão relacionadas com:

a) contato dos respondentes com conteúdos disponíveis no ambiente externo e que encontraram algum significado interno;

b) acolhimento de sugestões externas;

c) recuperação de experiências vividas;

d) reflexões individuais que geram novas interpretações pessoais; e

e) afinidade pessoal com o tema.

\subsection{Interpretação}

A segunda fase do processo de AO, denominada "Interpretação", é a etapa na qual o indivíduo explicita sua ideia de forma clara para si e para outros (CROSSAN; LANE; WHITE, 1999). Nessa fase, a linguagem desempenha um papel fundamental.

Nas narrativas, percebe-se que o fio que separa a fase da intuição da fase de interpretação é muito tênue. A relação entre essas duas fases segue num contínuo. No qual. Logo que a ideia surge, é explicitada e compartilhada com alguém. Nos discursos, pode-se perceber que, no início da contação da história, o tempo verbal é a primeira pessoa do singular - "eu pensei [...]" Ou "eu tive uma ideia [...]". Na continuidade, sem manifestação explícita sobre a inclusão de mais pessoas, a narrativa passa para a primeira pessoa do plural "daí nós conversamos [...]" Ou "aí pensei: vamos fazer uma campanha". Para os entrevistados, a passagem da 
"intuição" para a "interpretação" ocorre como se fosse um processo contínuo e natural, que se inicia com o surgimento de uma ideia e prossegue com o seu compartilhamento com alguém.

Nessa fase, ainda há certa imprecisão sobre os impactos da ideia e sobre como ela vai ser implementada. As citações a seguir ilustram esta forma imprecisa na passagem entre o "eu" e o "outro": "Foi uma ideia a partir do setor de referência (P2)" e "A gente não sabe o que vai ser ainda disso" (P2).

A fácil passagem da "intuição" para a "interpretação", na biblioteca estudada, segundo os informantes, está relacionada com a cultura organizacional. As narrativas mostram que existem, na biblioteca, um ambiente cultural favorável para a expressão de novas ideias e a abertura da chefia para que as mesmas sejam compartilhadas. Os entrevistados, em seus relatos, apontaram alguns fatores que contribuem para facilitar 0 compartilhamento de ideias:

\author{
[...] Dar abertura e ser receptivo. (P3) [referindo-se à postura da chefia] \\ [...] Nós temos uma cultura muito de ouvir os outros. (P3) \\ [...] Ter um planejamento não rígido facilita a implantação de ideias novas. (P3) \\ [...] Gestão [...] Mais horizontalizada. (P1) \\ [...] Dar abertura para as pessoas, a todo o momento, trazerem essas iniciativas e porem em \\ prática. (P3) \\ [...] O pessoal é bem aberto a novas ideias. (P6) \\ [...] Normalmente, depois de alguma reunião, surgem essas possibilidades de inovação. (P6)
}

\title{
5.3 Integração
}

A fase da integração refere-se ao momento em que ocorre uma troca mais intensa de ideias entre duas ou mais pessoas, que podem constituir uma equipe formal ou não, mas que interagem buscando encontrar uma compreensão compartilhada sobre o tema em questão (CROSSAN; LANE; WHITE, 1999). Trata-se de uma ação coletiva que pode evoluir para a construção de novos significados, ou seja, a partir da troca e discussão de ideias surgem novas configurações para a formalização de uma proposta de ação.

Sobre esta etapa, os relatos indicam que as discussões sobre uma ideia a ser implementada ocorrem de forma frequente e de diversas maneiras, como explicita P5:

\begin{abstract}
Elas ocorrem o tempo todo, em reuniões, atendendo usuários, conversando com chefias e colegas. A gente tem ideias e aprende o tempo inteiro, principalmente porque a gente tem muita interação. Essa troca é inerente à nossa função, proporciona isso no dia a dia. (P5)
\end{abstract}

Alguns relatos mostram que a ideia proposta inicialmente por uma pessoa, depois de compartilhada, se torna coletiva, ou seja, a autoria passa a ser de um setor ou grupo e não mais de um indivíduo:

A gente teve que mudar o que a gente inicialmente havia planejado e ir se adaptando também às dificuldades encontradas. (P2)

Isso foi no início, depois nós percebemos que era possível alinhar [...]. (P4)

Foi uma ideia a partir do setor de referência. (P2)

Nas nossas reuniões, isso ocorre muito e, especialmente, depois das reuniões com conhecimento ali trabalhado. Uma coisa é a conhecimento compartilhado ali na reunião e outra coisa é o conhecimento com que tu sais da reunião. Tu entras com um, sais com outro [...]. (P5)

Apesar de acontecer a integração de ideias de diversas formas, é nas reuniões formais para tomada de decisão que se alcança um nível maior de discussão e geração de novos conhecimentos: 
o conhecimento mais trabalhado e a gente compartilha mais. Cada um vem com um conhecimento e sai com outro conhecimento (P5).

O apoio da direção geral da biblioteca também foi citado como diferencial para que uma ideia compartilhada possa evoluir a caminho da sua implementação: "Então, a gente conseguiu levar essa ideia para a direção, que achou boa a intenção, a ideia, e apoiou desde o início" (P2).

O movimento mais individualizado também foi percebido em uma das narrativas. O entrevistado narra que teve uma ideia, apresentou-a para um grupo, que gostou, porém, o desenvolvimento dela estaria sendo realizado de maneira individual: "e as pessoas gostaram; então, a partir disso estou criando a estrutura dele..." (P3).

Em síntese, os relatos referentes ao processo de "integração" apontam para a importância de reuniões e trabalhos em equipes, onde as ideias são discutidas e reconstruídas coletivamente (novos insights). Os informantes destacam ainda que o posicionamento aberto dos gestores e a flexibilidade organizacional facilitam o processo. A análise dos dados permite afirmar que também ocorrem iniciativas individuais voltadas para a idealização de mudanças.

\subsection{Institucionalização}

O processo de institucionalização de uma ideia ocorre quando existe um grau de consenso ou entendimento entre os membros influentes da organização sobre os efeitos positivos da ideia e se procede à sua formalização, por exemplo, através de uma nova rotina ou de uma nova prática organizacional (CROSSAN; LANE; WHITE, 1999).

Nesse sentido, foi possível identificar, nas narrativas, que os entrevistados têm uma clara percepção do processo de institucionalização de uma ideia, conforme demonstram as citações:

Sim, as sugestões são ponderadas em grupo e homologadas e, depois de uma determinada experiência, se incorpora ao dia a dia. [...] As colegas propuseram, por exemplo, a construção de manuais, e isso foi acatado e adotado como padrão. (P6)

[...] Tem vários projetos que já têm uma periodicidade de acontecer e já estão institucionalizados. (P2)

[...] E isso [ajuste no modelo de administração dos estagiários] vem sendo feito há quatro anos. (P4)

A maioria [das ideias] a gente consegue aplicar, isso que é legal. (P5)

Uma das preocupações dos informantes com relação ao processo de institucionalização é a informalidade com que são tratadas algumas ideias. A análise das narrativas revela que existem processos ou rotinas que são executadas, porém, não estão formalizadas institucionalmente:

\footnotetext{
[...] Talvez faltasse um mecanismo menos informal de captar essas informações e institucionalizá-las de fato [...]. O máximo de formalidade que eu pude perceber são as atas de reuniões, que institucionalizam determinada decisão (P6)
}

[...] Às vezes a gente peca um pouco por não sistematizar os nossos processos. [...] Não tem os processos formalizados (P2).

A não formalização gera problemas de gestão. Um dos entrevistados relatou que a principal dificuldade em relação à falta de institucionalização de rotinas é a dificuldade de medir os resultados: "[...] Não tem, às vezes, muito como medir o resultado disso (P2)".

A análise dos dados permite afirmar que o processo de institucionalização é caracterizado por certo nível de informalidade, principalmente no estabelecimento dos padrões e rotinas. Decisões são tomadas, porém, carecem de institucionalização. 


\title{
5.5 Aprendizagem em rede
}

A aprendizagem na Biblioteca foi influenciada por relações externas a suas fronteiras. Algumas ideias que surgiram e foram aceitas no nível da Biblioteca envolveram interações com usuários e outros setores da universidade, como mostram as declarações abaixo:

\author{
[...] Os próprios usuários trazem sugestões e dúvidas. (P5) \\ Fizemos a parceria com o curso de cinema, que era recém-criado na [...], (P2) \\ Então, a partir disso estou criando a estrutura dele, vou levar para a SETIC, e eles vão \\ implementar agora, nas próximas semanas, para a estrutura da Biblioteca Central (P3).
}

Entretanto, apesar de algumas parcerias apresentarem resultados positivos, existem relatos sobre dificuldades de relacionamento entre a Biblioteca e outros órgãos ou setores da universidade. Essas dificuldades, muitas vezes, impossibilitam a implementação de inovações: "Assim, a gente tem uma autonomia muito grande aqui dentro. Por outro lado, o que depende de outros órgãos da universidade, a gente percebe dificuldades [...] Nos outros departamentos, não é assim" (P5).

A análise da articulação da BU com outros setores da instituição mostra e reforça aspectos da aprendizagem em rede. Autores como Argote e Ophir (2002) consideram que o desempenho de uma organização depende da articulação entre várias redes internas. Essa articulação se torna mais importante na medida em que se busca o desenvolvimento conjunto ou a transferência de conhecimento entre partes da organização, como pretende a BU. Diante dessa situação, é importante se considerar que o processo de aprendizagem (tanto individual quanto organizacional) é relacional e, portanto, emerge da interação entre atores individuais e organizacionais (MARIOTTI, 2012).

No caso analisado, a relacionalidade da BU com os demais órgãos da instituição foi considerada baixa, o que dificulta o processo de aprendizagem. A entrevistada P5, por exemplo, ressalta a importância das relações para ampliar as contribuições que a biblioteca pode oferecer à instituição como um todo:

[...] Acho que a biblioteca deveria ter mais representatividade junto à instituição, especialmente com a parte de tecnologia. Ontem mesmo, a gente estava usando um sistema que a SETIC desenvolveu e, ao usar o sistema, a gente percebeu vários problemas. Com a nossa demanda, eles já estão aperfeiçoando o que será de uso global. Então, se houvesse uma interação maior, poderíamos fazer mais trabalhos juntos. Tecnologia e informação têm tudo a ver.

Da mesma forma os cursos, os centros de ensino, as parcerias básicas com relação à compra de livros. Enfim, a gente ainda percebe muita dificuldade. As pessoas, às vezes, não têm o conhecimento sobre os próprios serviços que a biblioteca oferece. Então, a gente precisa, realmente, de uma representatividade maior junto aos departamentos, colegiados, para poder mostrar o nosso trabalho. (P5)

Pode-se afirmar que, segundo a percepção dos entrevistados, o processo de aprendizagem organizacional ocorre de maneira mais fluente no âmbito interno da biblioteca. Entretanto, existem barreiras à aprendizagem, devido à baixa interação com os demais setores da instituição. Tal fator indica a ausência, ou pouca ocorrência, de redes de aprendizagem internas que interliguem os conhecimentos organizacionais construídos nos diferentes ambientes/setores da instituição como um todo. Problemas relacionados ao compartilhamento e transferência de conhecimentos entre as bibliotecas e demais setores de instituições também foram diagnosticados em outros estudos (FAQUETI et al., 2015; DALL et al., 2014; CHEN, 2006, 2007; CHEN; LIN, 2008).

A partir da análise dos dados coletados, não foi possível identificar relacionamentos interorganizacionais que poderiam estar contribuindo para os processos de $\mathrm{AO}$. 


\section{Considerações finais}

A partir do estudo de Crossan, Lane e White (1999), foi possível identificar como os processos de intuição, interpretação, integração e institucionalização (4ls) ocorrem em uma Biblioteca Universitária.

A análise das narrativas permitiu observar que existem fatores e situações facilitadoras para que o ciclo de $A O$, que parte da geração de ideias até a sua institucionalização, aconteça.

Na primeira fase do modelo dos 4ls (intuição), constatou-se que o surgimento de ideias pode acontecer por duas vias: a) pela identificação de uma situação problema; ou b) pela identificação de oportunidade de melhoria de algum serviço sem que exista um problema real identificado. As fontes propulsoras das ideias são: leituras, estudos, participação em eventos externos (conhecimentos externos); resgate de experiências vividas; reflexões internas que geram uma ideia; e afinidade pessoal com o tema.

A segunda fase (interpretação), momento em que o indivíduo expressa suas ideias a outro, está intrinsicamente relacionada com a primeira (intuição). Diversas narrativas sobre a interpretação modificam a forma de expressão da primeira pessoa do singular - eu - para a primeira pessoa do plural - nós - como uma situação normal, que não necessita de maiores explicações. A conversação entre os bibliotecários sobre suas ideias parece ser livre e espontânea. Essas conversações e compartilhamentos ocorrem entre bibliotecários, entre bibliotecários e usuários, e entre chefias e demais servidores da biblioteca. Outro ponto relevante descrito pelos informantes são os fatores que mais contribuem para que eles se sintam com liberdade e motivados para explicitar suas ideias.

$\mathrm{Na}$ terceira fase (integração), em que se caminha de forma coletiva para o aprofundamento das discussões sobre uma ideia, os relatos mostram que a ideia inicial de uma pessoa, depois de compartilhada e reconstruída, torna-se coletiva, ou seja, a autoria passa a ser de um setor ou grupo e não mais individual. Destaca-se que a prática de reuniões formais para tomada de decisão contribui para melhorar o nível de discussão e gerar novos conhecimentos.

Sobre a quarta fase (institucionalização), foi possível identificar, nas narrativas, que os entrevistados percebem a existência do movimento que ocorre desde a geração de uma ideia até sua institucionalização. Segundo eles, a cultura dominante na biblioteca estudada favorece a geração e expressão de ideias, a interação entre os indivíduos e abertura da chefia para que as ideias sejam implementadas. Porém, eles destacam que existem atividades que são executadas, mas que não estão formalmente institucionalizadas; ou seja, não estão devidamente descritas e documentadas, compondo a memória organizacional.

Outro achado importante do estudo se refere à aprendizagem em rede - ao impacto do relacionamento da Biblioteca com outros órgãos ou setores da instituição no processo de aprendizagem. Apesar de acontecerem alguns relacionamentos que contribuem para a construção de aprendizagem colaborativa entre áreas da instituição, relatos apontam dificuldades neste quesito, o que prejudica, e até impossibilita, a implementação de melhorias ou inovações. A baixa relacionalidade e a pequena representatividade da biblioteca junto a órgãos ou setores da instituição foram causas apontadas como inibidoras da aprendizagem organizacional.

Dois fatores podem ser considerados como limitações deste estudo: a) os entrevistados selecionados executam funções de gestão intermediária na Biblioteca Central, ou seja, ocupam um espaço natural de liderança e são responsáveis por conduzir seus setores; e b) este estudo focou somente no movimento dos 4ls, que parte do nível individual para o nível institucional (feed-forward).

Como sugestões para futuras pesquisas propõe-se:

a) entrevistar ocupantes de outras funções visando ampliar o entendimento dos processos de $\mathrm{AO}$ em bibliotecas universitárias;

b) realizar estudos abrangendo o desenvolvimento da $\mathrm{AO}$ em bibliotecas que operam em estruturas multicampi, incluindo relacionamentos à distância;

c) aprofundar a discussão sobre a aprendizagem de bibliotecas a partir da perspectiva da aprendizagem em rede, tanto nos níveis intraorganizacionais como interorganizacionais; e

d) realizar novos estudos para compreender o processo de aprendizagem que flui no sentido feedback, em que a aprendizagem inicia nos conhecimentos organizacionais institucionalizados e segue para o nível individual. 


\section{Referências}

AMANTE, M.; PLACER, A. I. E.; COSTA, A. F. D. As bibliotecas universitárias na Sociedade do Conhecimento: o imperativo da colaboração. 2009. Disponível em: $<$ https://repositorio.iscteiul.pt/bitstream/10071/1561/1/edibcic comunicacao.pdf>. Acesso em: 15 maio 2016.

ANGELONI, M. T.; STEIL, A. V. Alinhamento de estratégias, aprendizagem e conhecimento organizacional. In: TARAPANOFF, K. (Org.). Aprendizagem Organizacional: fundamentos e abordagens multidisciplinares. Curitiba: IBPEX, 2011. V. 1.

ANTAL, A. B. Et al. Organizational learning and knowledge: reflections on the dynamics of the field and challenges for the future. In: DIERKES, M. Et al. (Org.). Handbook of organizational learning \& knowledge. Oxford: Oxford University Press, 2001.

ANTONELLO, C. S.; GODOY, A. S. Uma agenda brasileira para os estudos em aprendizagem organizacional. RAE, São Paulo, v. 49, n. 3, p. 266-281, 2009.

ANTONELLO, C. S.; GODOY, A. S. A encruzilhada da aprendizagem organizacional: uma visão multiparadigmática. RAC, Curitiba, v.1, n.2, p. 310-332, 2010.

ANTONELLO, C. S.; GODOY, A. S. Aprendizagem organizacional no Brasil. Porto Alegre: Bookman, 2011.

ARGOTE, L. Organizational learning research: past, present and future. Management Learning, v. 42, n. 4, p. 439-446, 2011.

ARGOTE, L.; OPHIR. R. Intraorganizational learning. In.: BAUM, J. A. C. (Ed.). The Blackwell Companion to Organizations. Oxford, UK: Blackwell, 2002. P. 181-207.

ARGYRIS, C.; SCHÖN, D. A. Organizational learning: a theory of action perspective. Massachussets: Addison-Wesley, 1978.

BONTIS, N.; CROSSAN, M.; HULLAND, J. Managing an organizational learning system by aligning stocks and flows. Journal of Management Studies, v. 39, n. 4, p. 438-469, 2002.

BRAUN, V.; CLARKE, V. Thematic analysis. In: COOPER, H. (Ed.). The Handbook of Research Methods in Psychology. Washington, DC: American Psychological Association, 2012.

BRAUN, V.; CLARKE, V. What can "thematic analysis" offer health and wellbeing researchers? International Journal of Qualitative Studies on Health and Well-being, [S.I.], v. 9, oct., 2014. Disponível em: <www.ijghw.net/index.php/qhw/article/view/26152>. Acesso em: 08 jul. 2016.

CARNEIRO, L. F. V.; SARO, J. A. V. A biblioteca como centro de recursos para a aprendizagem e investigação (CRAI) para apoio às tarefas de ensino e aprendizagem. In: BORGES, M. M.; CASADO, E. S. A ciência da informação criadora do conhecimento. Coimbra: Universidade de Coimbra, 2009. V. 1, p. 419-430.

CASTRO, G. De; COSTA, M. D. Gestão do conhecimento em bibliotecas no Brasil: um mapeamento temático com base na literatura técnico-científica. In: SEMINÁRIO NACIONAL DE BIBLIOTECAS UNIVERSITÁRIAS, 18, 2014. Belo Horizonte. Anais ... Disponível em: <https://www.bu.ufmg.br/snbu2014/wp-content/uploads/trabalhos/534-2333.pdf>. Acesso em: 05 out. 2015.

CUNHA, M. B. Da. A biblioteca universitária na encruzilhada. Datagramazero: Revista de Ciência da Informação, Rio de Janeiro, v. 11, n.6, dez. 2010. Disponível em: <http://www.dgz.org.br/dez10/Art_07.htm>. Acesso em: 18 ago. 2016.

CHEN, K. Library evaluation and organizational learning: A questionnaire study. Journal of Librarianship and Information Science, v. 38, n. 2, p. 93-104, 2006.

CHEN, K. Institutional evaluation and its influence on organizational learning. Aslib Proceedings, v. 59, n.1, p. 5-25, 2007.

CHEN, K.; LIN, P. Organizational learning in the evaluation procedures: A qualitative study. College \& Research Libraries, v. 69 , n. 1 , p. $36-49,2008$.

CROSSAN, M.; LANE, H.; WHITE, R. An organizational learning framework: from intuition to institution. The Academy of Management Review, v. 24, n. 3, p. 522-537, 1999.

CROSSAN, M.; MAURER, C. C.; WHITE, R. Reflections on the 2009 AMR decade award: do we have a theory of organizational learning? Academy of Management Review, v. 36 n. 3, p. 446-460, 2011.

CUNHA, M. B. Da. A biblioteca universitária na encruzilhada. Datagramazero: Revista de Ciência da Informação, Rio de Janeiro, v. 11, n.6, dez. 2010.

DALL, M. G. M. Et al. O profissional da informação e a comunidade acadêmica: imagens que dizem uma profissão. Revista ACB, v. 19, n. 2, p. 188-201, 2014.

EASTERBY-SMITH, M. Disciplines of organizational learning: contributions and critiques. Human Relations, v. 50, n. 9 , p.1085-113, 1997.

EASTERBY-SMITH, M.; LYLES, M. (Orgs.). Introduction: watersheds of organizational learning and knowledge management. In: (Ed.) Handbook of organizational learning and knowledge management. Malden: Wiley-Blackwell, 2005. P.1-15. 
FAQUETI, M. F. Et al. Compartilhamento e transferência de conhecimento na gestão de bibliotecas: um estudo em instituições federais de ensino de Santa Catarina. Revista ACB, Florianópolis, v. 20, n. 2, p. 567-583, set./dez., 2015.

FAQUETI, M. F; ALVES, J. B. Da M.; STEIL, A. V. Aprendizagem organizacional em bibliotecas acadêmicas: uma revisão sistemática. Perspectivas em Ciência da Informação, v.21, n.4, out./dez. 2016.

FIGUEIREDO, A. D. De. Regresso ao futuro: 500 anos depois. In: CONGRESSO INTERNACIONAL A BIBLIOTECA DA UNIVERSIDADE: PERMANENCIAS E METAMORFOSES. 16-18 jan. Anais... Coimbra, 2014. Disponível em: <http://pt.slideshare.net/adfigueiredopt/bibliotecas-universitarias-regresso-ao-futuro>. Acesso em: 17 ago. 2015.

FIOL, C. M.; LYLES, M. A. Organizational learning. The Academy of Management Review, v. 10, n. 4, p. 803-813, 1985.

FUJITA, M. S. L. Aspectos evolutivos das bibliotecas universitárias em ambiente digital na perspectiva da rede de bibliotecas da UNESP. João Pessoa, Inf. \& Soc., v. 15, n.2, p.97-112, 2005.

FLUSSER, Victor. A biblioteca como um instrumento de ação cultural. Revista da Escola de Biblioteconomia da UFMG, v. 12, n. 2, 1983.

KNIGHT, L. (2002). Network learning: exploring learning by inter-organizational networks. Human Relations, v. 55, p. 427-454, 2002.

LUBISCO, N. M. L. Bibliotecas Universitárias, seus serviços e produtos: transposição de um modelo teórico de avaliação para um instrumento operacional. Salamanca, 2014. (Relatório de pesquisa pós-doutoral). Disponível em: <www.portalseer.ufba.br/index.php/revistaici/article/viewfile/12834/9273>. Acesso em: 20 set. 2015.

LÜCK, E. Et al. Biblioteca universitária e as diretrizes curriculares do ensino de graduação. In: SEMINÁRIO NACIONAL DE BIBLIOTECAS UNIVERSITÁRIAS, 12, 2000. Florianópolis. Anais... Disponível em: <http://snbu.bvs.br/snbu2000/parallel.html>. Acesso em: 05 out. 2015.

MALHOTRA, N. Pesquisa de marketing: uma orientação aplicada. Porto Alegre: Bookman, 2001.

MARCH, James G. Exploration and exploitation in organizational learning. Organization science, v. 2, n. 1, p. 71-87, 1991.

MARIOTTI, F. Exploring interorganizational learning: a review of the literature and future directions. Knowledge and Process Management, v.19, n. 4, p. 215-221, 2012.

MINAYO, M. C. De S (Org.). Pesquisa social: teoria, método e criatividade. 29. Ed. Petrópolis, RJ: Vozes, 2010.

MOZZATO, A. R.; GRZYBOVSKI, D. Cooperação interorganizacional e novos formatos organizacionais: a inclusão do nível interorganizacional no continuum da aprendizagem. In: ENCONTRO NACIONAL DA ANPAD, Rio de Janeiro, Anais... Rio de Janeiro, 2011.

RIBEIRO, R. M. R.; CAVALCANTE, C. Ação cultural em bibliotecas universitárias: um serviço da seção de referência como instrumento de interação social no sistema de bibliotecas da universidade estadual de feira de santana (SISBI-UEFS). In: SEMINÁRIO NACIONAL DE BIBLIOTECAS UNIVERSITÁRIAS, 18, 2014. Belo Horizonte. Anais ... Disponível em: < https://www.bu.ufmg.br/snbu2014/wp-content/uploads/trabalhos/70-1716.pdf>. Acesso em: 05 out. 2016.

RODRIGUES, D. S. Et al. Cinema ao meio-dia: ação cultural em bibliotecas universitárias. RBBD. Revista Brasileira de Biblioteconomia e Documentação, São Paulo, v. 11, n. 2, p. 155-172, 2015.

SANCHES, G. A. R.; RIO, S. F do. Mediação da Informação no fazer do bibliotecário e seu processo em bibliotecas universitárias no âmbito das ações culturais. Incid: Revista de Ciência da Informação e Documentação, v. 1, n. 2, p. 103$121,2010$.

SANTOS, M. C. F.; CATARINO, M. E. 25 anos da web e o marco civil da internet: o livre acesso à informação, a liberdade de expressão e a privacidade. Comunicação \& Informação v. 19, n. 1, p. 05-19, 2016

SILVA, M. De A. P.; SOUZA, L. M. S. De; MORAIS, L. De S. Biblioteca e ação cultural: apontamentos conceituais a partir da experiência na Universidade Federal de São Carlos. Informação \& Sociedade, v. 9, n. 1, 1999.

SNYDER, W. M.; CUMMINGS, T. G. Organization learning disorders: conceptual model and intervention hypotheses. Human Relations, v. 51, n. 7, p. 873-895, 1998.

STEIL, A. V. Et al. An approach to learning in virtual organizations. In: SIEBERT, Pascal; GRIESE, Joachim (Ed.).

Organizational Virtualness and Electronic Commerce. Bern: Simowa Verlag Bern, 1999. 


\section{Dados dos autores}

Marouva Fallgatter Faqueti

Formada em Biblioteconomia e Documentação, Mestre em Engenharia de Produção e doutoranda no Programa de Pós-Graduação de Engenharia e Gestão do Conhecimento pela Universidade Federal de Santa Catarina. marouva@ifc-camboriu.edu.br

\section{Sigrid Karin Weiss Dutra}

Formada em Biblioteconomia e Documentação, Mestre em Engenharia de Produção pela Universidade Federal de Santa Catarina.

sigrid.k.weiss@ufsc.br

João Bosco da Mota Alves

Professor do Programa de Pós-Graduação de Engenharia e Gestão do Conhecimento, da Universidade Federal de Santa Catarina (EGC/UFSC).

joao.bosco.mota.alves@ufsc.br

Cristiano José Castro de Almeida Cunha

Professor do Programa de Pós-Graduação de Engenharia e Gestão do Conhecimento, da Universidade Federal de Santa Catarina (EGC/UFSC).

cunha@egc.ufsc.br

Recebido - Received: 2016-07-18

Aceitado - Accepted: 2017-03-19

\section{(cc) EY}

This work is licensed under a Creative Commons Attribution 4.0

United States License.

\section{ULLS D-Sorke}

This journal is published by the University Library System of the University of Pittsburgh as part of its

D-Scribe Digital Publishing Program and is cosponsored by the University of Pittsburgh Press. 